\title{
Social Variables and Dropout Tendencies among Secondary School Students in Ikom Education Zone, Cross River State, Nigeria
}

\author{
Joy N. Njoku ${ }^{1}$, Edna A. Osang ${ }^{1} \&$ Blessing A. Ntamu ${ }^{1}$ \\ ${ }^{1}$ Department of Educational Foundations, University of Calabar, Cross River State, Nigeria \\ Correspondence: Joy N. Njoku, Department of Educational Foundations, University of Calabar, P.M.B 1115 \\ Calabar, Cross River State, Nigeria.
}

Received: March 14, 2020

Accepted: April 28, $2020 \quad$ Online Published: July 23, 2020

doi:10.5539/ies.v13n8p88

URL: https://doi.org/10.5539/ies.v13n8p88

\begin{abstract}
This study was on social variables and dropout tendencies among secondary school students in Ikom education zone, Cross River State, Nigeria. The social variables considered were substance abuse, family type and teacher/students relationship. Out of population of 7228 students, sample of 506 students were randomly selected for the study. A survey design was adopted. The instrument used for data collection was questionnaires titled 'Social Variables and Dropout Tendencies Questionnaire'. Three hypotheses were formulated and tested at .05 level of significant. The statistical tools used are Pearson Product Moment Correlation Coefficient and Independent t-test. The results showed that there was significant relationship between (i) substance abuse and dropout tendencies. (ii) family type and dropout tendencies (iii) teacher/student relationship and dropout tendencies. The results were discussed and the researchers recommended that: (i) students be monitored and counseled against substance abuse both at home and in school. (ii) parents should for the sake of their children stay together and train them. (iii) teachers should create conducive and favourable environment for the students to learn.
\end{abstract}

Keywords: substance, family, relationship, dropout, secondary

\section{Introduction}

\subsection{Background to the Study}

Dropout tendencies among students at secondary school level are a major challenge to education stake holders in the $21^{\text {st }}$ century. Education is the most potent weapon to fight illiteracy, ignorance, poverty and under-development of any individual or society. Education helps in building the capacity of an individual to acquire appropriate information, skills and competencies for personal survival, development and national transformation. It is by this understanding that governments all over the world are trying to ensure that their citizens are provided educational opportunities irrespective of gender, age or disabilities.

In Nigeria there is free and compulsory education at junior secondary school level to enable every child has access to at least basic education. The need to educate every child has become obvious since they are the leaders of tomorrow. However, the free and compulsory basic education has not yielded the maximum desire to eradicate illiteracy in the society since many children do not stay through the period of training required. Many children particularly in the study area drop out from school before their graduation time. This has slowed down the rate of technological and manpower development in the area and nation at large.

School dropout is a social issue plaguing the educational system and the society at large. School dropout is an untimely exit from school resulting to inability of such a child to acquire relevant skills, attitude, techniques and knowledge expected from him/her. This research aims at investigating how social variables like substance abuse, family type and teacher/students relationship can influence students' dropout tendencies.

Obikwelu (2008) described dropout tendency among students as a strong desire born in their heart to leave the school system before normal graduation period. It is a kind of drive that pulls students out of their academic pursuit before normal graduation period or end of their academic programme. Many students who are victims of this circumstance end up putting their hands into many dirty deals like forgery of certificates and other vies to see if they can succeed in life.

Parker (2003) described dropout tendencies as worrisome challenge to families and the government at large. This 
is due to the realization of the social problems this condition can generate in the society. A situation where a large number of youths roam the streets without relevant skills will be a danger to the people. Some of these students go into stealing, prostitution, cultism, drug abuse extortion of innocent victims and so on; many researchers like Ogumaro (2009) have investigated on the possible causes of school dropout tendencies among secondary school students. They came up with factors such as poverty, unwanted pregnancy, poor teaching methods and peer influence. Since this problem has continued unabated, the researchers deemed it necessary to investigate the effect of other social variables such as substance abuse, family type, teacher/student relation on school dropout tendencies in the study area.

Substance abuse in the context of this paper is the inappropriate consumption of food and none food substances to the detriment of one's health and wellbeing. These substances include drugs, drinks, cigarettes, petrol and so on. Selda (2010) carried out a research to investigate why students drop out of school. He adopted interview and observation methods to study nineteen young adults between age 15-24. He found out that alcohol consumption accounted for $51 \%$ of school dropout. This means that alcohol consumption increased the tendencies for student dropout of school. Obogo and Njoku (2017) also blamed dropout tendencies among students on smoking and alcoholism in their research on "Gender, depression and drug abuse among secondary school students".

Obot, Ibagam, Ojiji, and Wai (2001) in their study using 29 out of school adolescents in Jos, Nigeria found out that $38.7 \%$ of the respondents were already long time alcohol addicts. However, McCaffrey et al. (2010) carried out a study on marijuana use and high school dropout using a descriptive research design. They found out that there were some other factors like peer and family social influence, attachment to conventional institutions and emotional distress that equally influenced dropout tendencies among the students.

Valkov (2018) carried out a research on "school dropout and substance use: consequence or predictor?" He found out that through literature many researchers believed that substance abuse is a consequence of dropout challenges, some others noted that substance abuse predicted drop out tendencies while a third group believed that substance abuse and dropout tendencies are not causal but are influenced by a third variable According to these researchers dropout tendencies among students is a multi-variable predictor problem. This also informed the researchers' decision to investigate other variables like family type.

Family type by the researchers' definition connotes single parent family versus intact family where father and mother are together raising their children. Song et al. (2012) conducted a research investigating "dropout of high school: The effects of family structure and family transitions" they found out that divorce and separations have negative effect on high school students but staying married does not hurt the students. By implication intact families have children who are more likely to finish school than divorced and separated couples.

In the same vein, Malima and Akech (2016) in a research on effect of single parenting on students' academic performance in secondary schools observed that single parenting negatively affect academic performance of secondary school students. This can bring discouragement on the part of students which can lead to dropping out of school.

In another research, Amato, Patterson, and Brett (2015) investigated single parenthood and children's educational achievements. They found out that single parenthood did not significantly influence test scores rather maternal economic status influenced students' performance. This can be explained by the fact that a poor single parent will find it difficult to provide all the requirements that will support the child's success in school.

Parents are expected to raise their children train and show them love but where these responsibilities are left for one of the couple it may be an overwhelming task for that person. The school supposed to be another hope of comfort for children, however, it is not always so. Some teachers exhibit good and caring relationship with the student while some do not. This research will also assess the relationship between teacher/student relationship and dropout tendencies of secondary school students.

Teacher/student relationship is the degree of acceptance, co-operation and tolerance that exist between teachers and their students. The nature of this relationship can attract or repel students from schools. Positive relationship creates conducive environment for learning, so it should not be compromised. Bajrachenya (2015) investigated impact of teacher-student communication on high risk dropout among students in Nepal, South Asia and came up with the result that lack of communication between teachers and students was among the highest causes of school dropout. Every stakeholder in education desires that students register and stay through their programmes. Dropping out of schools leads to great loss in man power and finance.

Lester and Cross (2015) examined the relationship and emotional wellbeing and factors pertaining to school climate, focusing on the domains of safety, social relationship and social connectedness in the last year of 
primary school and first two years of secondary school. They used self-completion questionnaire to collect data from 1,800 students 4 times over 3 years. The students were aged 11-14 years. Multi-level modeling was used to analyze data for each of the variables. The result showed that peer support was the strongest predicator of wellbeing in the last year of primary school while feeling safe at school was strongest predictor of wellbeing in the first 2 years of secondary school. They concluded that feeling safe at school, feeling connected to school and peer support predicted wellbeing of students.

The researchers therefore wish to investigate the relationship between social variables like substance abuse, family type and teacher/student relationship on dropout tendencies among secondary school students in Ikom, Cross River State, Nigeria. Ikom is a commercial city and shares boundary with the Republic of Cameroon. The number of school children who roam the streets and hawk all kinds of commodities is alarming. Some research works have been done on the effect of poverty and parents level of education on dropout tendencies in the area. The researchers therefore wish to restrict the research to relationship between substance abuse, family type and teacher/students relationship and dropout tendencies in the area.

\subsection{Objectives of the Study}

The general objective of this study is to investigate the relationship between social variables and dropout tendencies among secondary school students in Ikom education zone, Cross River State, Nigeria. Specifically the study will investigate relationship between;

1) Substance abuse on dropout tendencies among secondary school students in Ikom.

2) Family type (single parenting and intact family) on dropout tendencies among secondary school students in Ikom.

3) Teacher/student relationship among secondary school students in Ikom.

\subsection{Hypotheses}

To guide this research three hypotheses were formulated as follows:

1) There is no significant relationship between substance abuse and dropout tendencies among secondary school students in Ikom educational zone, Cross River State, Nigeria.

2) There is no significant influence of family type and dropout tendencies among secondary school students in Ikom educational zone, Cross River State, Nigeria.

3) There is no significant relationship between teacher/student relationship and dropout tendencies among secondary school students in Ikom educational zone, Cross River State, Nigeria.

\subsection{Importance of the Study}

This study is very important to every stake holder in education sector in the study area. It will help students understand the risk inherent and dangers of substance abuse to their educational aspiration. The teachers and school administrators will also study the findings of this research as working material that will help them in identifying this problem and proffer solutions. The research will also be useful to parents who may understand the dangers of raising children in broken homes.

\section{Research Method}

This section explained the various steps used in conducting the research. It specifically considered the research design, the population of the study, the sampling technique, the sample, instrumentation, procedure for data collection and analysis

\subsection{Sampling Procedures}

\subsubsection{Sampling Technique}

Stratified random sampling technique was used to select the respondents who formed the sample. Ikom educational zone was stratified into six strata according to the local government areas. Since there were varied numbers of schools among the strata, the researchers used $20 \%$ of schools in each stratum. This amounted to 17 schools selected. In the same way $7 \%$ of the students were randomly selected from each school that was selected.

\subsubsection{Sample}

A total of 506 Senior Secondary School students participated in the research. 
Table 1. Population of the study

\begin{tabular}{cccc}
\hline s/n & Local government area & No. schools & No. of students \\
\hline 1 & Yakurr & 14 & 1096 \\
2 & Ikom & 16 & 1531 \\
3 & Obubra & 13 & 1253 \\
4 & Etung & 10 & 1049 \\
5 & Boki & 18 & 1237 \\
6 & Abi & 11 & 1062 \\
& Total & 84 & 7228 \\
\hline
\end{tabular}

Table 2. Sample of the study

\begin{tabular}{cccc}
\hline s/n & Local government area & No. schools & No. of students \\
\hline 1 & Yakurr & 3 & 77 \\
2 & Ikom & 3 & 107 \\
3 & Obubra & 3 & 88 \\
4 & Etung & 2 & 73 \\
5 & Boki & 4 & 87 \\
6 & Abi & 2 & 74 \\
& Total & 17 & 506 \\
\hline
\end{tabular}

\subsection{Instrumentation}

The instrument used for data collection in this study was a questionnaire titles 'Social Variables and Dropout Tendencies questionnaire' which was validated by three experts one each from Educational psychology, Measurement and evaluation and Sociology of education. The instrument was judged to have good face validity.

The reliability of the instrument was established by carrying out pilot study using students that were not part of the study using Cronbach Alpha procedure. The reliability coefficient ranged from .73 to .78 . The instrument was administered to the respondents by the researchers after obtaining permission from the school head teachers in the various schools assisted the researchers to make sure that their students respond honestly to the questions as it concerns them. After retrieving the completed questionnaires, the researchers coded the responses and subjected them to analysis using Pearson Product Moment Correlation Coefficient for hypotheses 1 and 3 and independent t-test for hypothesis 2 . The results are as shown in Table 3, 4 and 5 respectively.

\subsection{Research Design}

The researchers adopted the survey design for this study. This design is most appropriate because it helped the researchers use questionnaires and to systematically collect data from the respondents who represent an entire population. This is also good for a large sample as used in this research.

\section{Results}

Table 3. Pearson product moment correlation coefficient showing relationship between substance abuse and school dropout tendencies among secondary school students

\begin{tabular}{ccccccc}
\hline Variable & $\mathrm{N}$ & $\mathrm{X}$ & $\mathrm{SD}$ & $\mathrm{df}$ & $\mathrm{r}-\mathrm{cal}$ & $\mathrm{Sig}$. \\
\hline Substance abuse & 506 & 13.82 & 5.23 & \multirow{2}{*}{504} & .103 & .021 \\
Dropout tendencies & 506 & 13.64 & 4.93 & & & \\
\hline
\end{tabular}

The result in Table 3 above shows that there is a significant relationship between substance abuse and dropout tendencies among secondary school students in Ikom education zone, Cross River State, Nigeria. The value of "r" calculated (.103) is greater than the critical value (.021), by this result the null hypothesis is therefore rejected. This means that increase in substance abuse leads to increase in school dropout tendencies. 
Table 4. Independent t-test showing the influence of family type (single parenting/intact) on dropout tendencies among secondary school students

\begin{tabular}{ccccccc}
\hline Variable & $\mathrm{N}$ & $\mathrm{X}$ & $\mathrm{SD}$ & $\mathrm{df}$ & $\mathrm{r}-\mathrm{cal}$ & Sig. \\
\hline Single parenting & 309 & 14.50 & 5.83 & \multirow{2}{*}{504} & 2.53 & .021 \\
Intact family & 196 & 13.29 & 4.19 & & & \\
\hline
\end{tabular}

The result in Table 4 shows that the mean of students with single parents is higher than that of students with intact families where the parents are together and when it was tested using independent t-test the result also showed that "t" calculated (2.53) is higher than the critical value (.021). the null hypothesis is thereby rejected.

Table 5. Pearson product moment correlation coefficient showing relationship between teachers/student relationship and dropout tendencies among secondary school students

\begin{tabular}{ccccccc}
\hline Variable & $\mathrm{N}$ & $\mathrm{X}$ & $\mathrm{SD}$ & $\mathrm{df}$ & $\mathrm{r}-\mathrm{cal}$ & Sig. \\
\hline Teacher/student relationship & 506 & 15.11 & 3.33 & 504 & -.342 & .062 \\
Dropout tendencies & 506 & 14.06 & 5.32 & & & \\
\hline
\end{tabular}

The result in Table 5 showed that $\mathrm{r}$-cal is -.342 while the critical value is .062 at .05 level of significant and 504 degree of freedom. This implies that the calculated value has a negative value of -.342 while the critical value of "r" is .062. The negative relationship here shows that when teacher/student relationship increase or improve dropout tendencies will decrease or reduce but when teacher/student relationship decreases, dropout tendencies increase. By this result the null hypothesis is therefore rejected.

\section{Discussion}

\subsection{Discussion of Findings}

The result of the hypothesis testing on the influence of substance abuse on dropout tendencies of secondary school students in the research showed that there is a significant relationship between substance abuse and dropout tendencies among the students. This implies that the more students' abuse substances like alcohol, marijuana, cigarette, cough syrup and others, the more likelihood of dropping out of school by the students before completion of their academic programme. This is in line with the findings of McCaffrey et al. (2010), who found a relationship between marijuana use and dropout tendencies among high school students. Akanbi et al. (2015) also reported a negative effect of substance abuse on students of college of education. This result can be due to high economic and psychological implications of substance abuse. Some of the students cannot cope with financing their addiction and meeting the school financial requirement. Some of the substances also alter the cognitive functioning of the students making it impossible for them to cope with academic work. This however has been an object of debate among researchers because some like Dee and Evans (2003) believed that alcohol use by teenagers does not have any significant impact on their education. In the same vein, Gabriel (2001) demonstrated that the actual effect of drinking by youths on their academic is very insignificant.

The result of hypothesis two on the effect of family type (single parenting and intact families) on dropout tendencies of secondary school students also showed a significant relationship between family type and dropout tendencies. Students who are raised by a single parent have more tendencies to drop out of school irrespective of whether it is the mother or father. However most children raised by a single parent were raised by their mothers. In a similar study by Song et al. (2012) they concluded those single parenting affect students' performance and staying through school. They also reported that students raised by only mothers were doing better than students raised by only their fathers. It is necessary that parents stay together to train their children since each of them has significant roles to play in the life of the children.

The last finding of this study showed that teacher/student relationship also has a significant influence on dropout tendencies of secondary school students. This implies that students whose teachers are unapproachable and emotionally are more likely to drop out of school. The school is the second home of the students and teachers are like parents to them. If the relationship between the teachers and students are not cordial, students will find reasons to stay away from school. Some students do not like school because of fear of their teachers. Whannell and Allen (2011) also arrived at a similar result on their investigation on influence of teacher/student relationships on academic outcomes of students. Students who have poor communication channels with their teachers are more likely to drop out of school. Contrary to this finding, Lessard et al. (2004) in their research 
reported that teacher/student relationship does not influence dropout tendencies rather it affects achievement in school.

A good inter-personal relationship boosts confidence and peace of mind. This will make the students to desire to stay in school and finish their programme.

\subsection{Conclusion}

Dropout tendencies among secondary school students are a major social problem in the research area and many parts of the world today. It is very important that students register and stay through school to obtain the needed certificate, skill and morals. Many factors have contributed to students desiring to leave school before completing their required programme, such factors as found in this research are substance abuse, family type and teacher/students relationships. All the three variables have significant relationship with dropout tendencies among secondary school students. Dropout tendencies increased with substance abuse, single parenting and poor teacher/student relationship.

\subsection{Recommendations}

Having considered and discussed the findings of this research logically. The researchers recommend that:

- Students are monitored and counseled against substance abuse early from home, and the school should continue from where they have stopped.

- Parents should try for the sake of their children to stay together and raise their children.

- Teachers should create a very favorable and conducive, physical and psychological atmosphere for the students to study.

\section{References}

Akanbi, M. I., Augustina, G., Theophilus, A. B., Muritala, M., \& Ajiboye, A. S. (2015). Impact of Substance Abuse on Academic Performance among Adolescent Students of Colleges of Education in Kwara State, Nigeria. Journal of education and practice, 6(28), 108-112.

Amato, P. O., Patterson, S. \& Brett, B. (2015).Single parent household and children's educational achievement. A state level analysis. Social Science Research, 53, 191-202. https://doi.org/10.1016/j.ssresearch.2015.05.012

Bajrachenya, D. (2015). Current situation and challenges in achieving EFA goals: the case of Nepal. Journal of Graduate School Humanities and Science, 17, 191-199.

Dee, F. \& Evans, M. (2003).Status of alcohol and drug education in Oregon schools (Unpublished thesis). University of Oregon.

Gabriel, K. M. (2001). Status of alcohol and drug education in Oregon schools. Nicroform in publication, Oregon.

Lessard, A., Fortin, L., Joly, J., Royer, É., \& Blaya, C. (2004). Students at-risk for dropping out of school: Are there gender differences among personal, family and school factors. Journal of at-risk issues, 10(2), 91-127.

Lester, L., \& Cross, D. (2015). The relationship between school climate and mental and emotional wellbeing over the transition from primary to secondary school. Psychology of Well-being, 5(1), 9. https://doi.org/10.1186/s13612-015-0037-8

Malimah, J. G., \& Akech, P. E. (2016). The effect of single parenting on students academic performance in secondary schools in Arusha, Tanzania. Masterarbeit Tanzania.

McCaffrey, D. F., Liccardo Pacula, R., Han, B., \& Ellickson, P. (2010). Marijuana use and high school dropout: the influence of unobservables. Health economics, 19(11), 1281-1299. https://doi.org/10.1002/hec.1561

Obikwelu, D. (2008). The classroom as an emotional health centre. The Educational Magazine, 31, 8-11.

Obogo, G. O., \& Njoku, J. N. (2017). Gender, depression and drug abuse among senior secondary school students in Calabar Education zone, Cross River State, Nigeria. European Journal of Education Studies, 3(1), 387-395.

Obot, I. S., Ibadam, A. J., Ojiji, O. O., \& Wai, P. (2001). Alcohol, Gender and drinking problem. WHO publications, https://who.int>publications

Ogumaro, N. (2009). Social psychological mechanism affecting school dropout. West African Journal of Education, 6(5), 36-40.

Parker, A. (2003).Identifying predictors of academic persistence in distance education USDLA Psychology, 
$10(2), 46-52$.

Selda, T. (2010). Reasons why most students drop out of school. Journal of Educational Psychology, 98, 1-13.

Song, C., Benin, M., \& Glick, J. (2012). Dropping out of high school: The effects of family structure and family transitions. Journal of Divorce \& Remarriage, 53(1), 18-33. https://doi.org/10.1080/10502556.2012.635964

Valkov, P. (2018). School dropout and substance use: consequence or predictor. Trakia Journal of Sciences, 16(2), 95. https://doi.org/10.15547/tjs.2018.02.004

Whannell, R., \& Allen, W. (2011). High School Dropouts Returning to Study: The Influence of the Teacher and Family during Secondary School. Australian journal of teacher education, 36(9), 22-35. https://doi.org/10.14221/ajte.2011v36n9.3

\section{Copyrights}

Copyright for this article is retained by the author(s), with first publication rights granted to the journal.

This is an open-access article distributed under the terms and conditions of the Creative Commons Attribution license (http://creativecommons.org/licenses/by/4.0/). 